\title{
There Is Still No "Fit for All" IS Development Method: Business Development Context and IS Development Characteristics Need to Match
}

\author{
Tomi Dahlberg \\ Turku School of Economics at the University of \\ Turku \& Aalto University School of Business, Finland \\ tomi.dahlberg@utu.fi
}

\begin{abstract}
Information systems development has returned to strategic management due to the increase of softwareenabled businesses. We investigated two failed IS development projects using the exploratory case study method. One of the projects was executed with the plan-driven approach methods and the other with the change-driven (agile) approach methods. Data analysis showed that both projects followed the principles of the selected methods. That, however, was not enough. The plan-driven project achieved project objectives but did not deliver business value and the IS was never taken into use. The change-driven project delivered desired business value but failed to release a robust IS. Our main contribution to research is our proposition to match the characteristics of IS development methods with the characteristics of business development contexts. We also disclose some novel reasons for IS project failures.
\end{abstract}

\section{Introduction}

Organizations had to largely develop information systems (IS) internally until the last decade of the $20^{\text {th }}$ century. The objective was, and still is, to support the execution of an organization's strategy and business. After the 1990s, most organizations replaced internally developed ISs with ISs purchased from IS vendors. IS development was outsourced and/or discontinued since it was no longer considered strategic. The rapid growth of IS driven businesses appears to have turned the tide again. In digitalization visions, even physical products (e.g. cars) and facilities (e.g. utility networks) are considered as platforms for IS and digital data driven services. Organizations have started to reconsider IS development insourcing and/or contracting to embrace digital business. Thus, IS development has re-emerged to the agenda of strategic management. The selection of IS development method(s), the focus of the present article, is one of the key decisions to be made.

\author{
Altti Lagstedt \\ Turku School of Economics at the University of \\ Turku, Rehtorinpellonkatu 3, 20500 Turku, Finland, \\ aeelag@utu.fi
}

The profession of IS development (r)evolves all the time. New methods, techniques and tools are introduced. Despite of this, the majority of IS projects continue to fail. According to the Standish Group, the success rate of IS projects has improved only by 5-10 $\%$ within 35 years, since the early 1980s to current times. During the 80 s and 90 s, $20-25 \%$ of IS projects adhered to timetables and budgets, and delivered the agreed functionalities. During the 2010s, 30-35\% of IS projects have succeeded, $45-50 \%$ have been challenged / troubled and the remaining $20 \%$ have failed [19, 45]. Despite of the critique on Chaos reports [e.g. 16], other studies have reported similar findings [e.g. 29]. Several efforts to improve the success rate of IS projects have been taken. These include e.g. the following:

- The findings of research on IS project failure reasons. Failure reasons are often labelled as IS project risk items, which are classified into risk categories/ factors over the lifecycle of IS projects. For example, Nelson [34] identified 36 reasons for IS project failures, classified them into four IS project risk categories and noted that IS project estimation was the most difficult phase [34], see also [1, 5]. IS project risk mitigation is the other key topic of this research line. The purpose is to provide checklists concerning potential IS project risks with means to mitigate each risk. For example, Standish Group has compiled a list of 100 potential risk items divided into 10 groups, and has suggested risk mitigation means to each risk item [45]. A typical IS development method is updated from time to time and pays a lot of attention to (newly discovered) IS project risk items and their mitigation.

- Comprehensive project management methods, such as PMBOK and PRINCE2, have been crafted and become widely used. Their objective is to improve the skills of project managers, steering committees and project teams to plan and to execute projects. Project portfolio management and project management offices are seen as useful means to better manage (IS) projects.

The above-mentioned methods are based on the socalled plan-driven approach. The waterfall model [37] is probably the best known method. In the plan-driven 
approach, (IS) development steps are consecutive. The assumption is that the desired outcomes/functionalities of an IS project can be modelled/specified accurately at the beginning of the project and then developed during the consecutive steps. However, this has proved to be true quite seldom. [see e.g. 25]. Consequently, alternative IS development methods, such as SCRUM, XP and DEVOPS, have been crafted. The approach of these methods is labelled agile or change-driven. We use the latter term. The roots of the change-driven methods are in iterative and prototype IS development.

Change-driven (IS) development methods are advocated as the solution to the limitations of plandriven methods [see e.g. 18, 45]. Standish Group's annual Chaos reports support this claim partially. For example, in 2015, the success rate of change-driven projects was $39 \%$ whereas $11 \%$ of plan-driven projects succeeded [19]. Standish Group considers the use of the change-driven methods as the main driver behind the recent 5-10\% improvement in IS project success rate [19]. Some IS practitioners have even proposed that only change-driven methods should be used.

Nevertheless, the 2015 Chaos report showed that the majority of change-driven projects (61\%) still failed or were troubled. One obvious reason for the failure is the selection of an unsuitable IS development method and/or inexperience with the method, which may contribute to other failure reasons. Prior studies [e.g. 4, 12, 23, 25, 34] have, indeed, discovered several direct and indirect IS development method related reasons for failures. We investigated two failed IS development projects: one executed with plan-driven and the other with change-driven methods. In the analysis of the project outcomes, it was necessary to evaluate how well each project followed the guidelines of the selected methods. In later sections of the article, we will show that the projects employed experienced persons and followed carefully the guidelines of the chosen methods. The IS development method related reasons for project failures discussed by prior research did thus not explain the failures of the projects. We concluded that doing things right may not be enough to ensure project success. This motivated us to search answer to the question, what then does?

Prior research and efforts to develop better IS development methods have addressed extensively the various characteristics of these methods and IS projects, as well as reasons for IS project failures. We adopted a different approach since we deemed that there is a research gap in matching the characteristics of IS development methods and business development contexts. We regard IS development as an integral part of organizational development. Consequently, we propose that the characteristics of the selected IS development methods should match with the characteristics of the business development context, most notably with business execution and outcome uncertainties. This is in line with [11], who discovered that factors outside of the IS project domain were the most important determinants for IS project success and jointly with project factors explained close to $50 \%$ of project success. The purpose of the present article is to examine the reasons for project failures, especially those related to business development contexts. Against this backdrop, we also investigate why the two projects were considered failures, that is, how the success of an IS project was understood in the projects.

The generic research problem of our study is to investigate relations between plan-driven and changedriven IS development methods and their business development contexts. From this generic research problem, we formulate the following three research questions for this study:

RQ1: What business development contexts, and/or other novel reasons for failure were related to the failures of the two investigated projects?

RQ2: What were the expected business and other success measures of the two investigated projects?

RQ3: What tentative suggestions can be made on the selection of plan-driven or change-driven IS development methods so that the characteristics of the method and the business development context match?

To answer these research questions, the article is organized as follows: as the theoretical background we review the characteristics of plan-driven and change driven (IS) development methods and their business development contexts (business execution and outcome uncertainties) as well as the success measures of (IS) projects. Chapter three discusses the methodology used to collect and analyse empirical data. Research findings are presented in chapter four and we end the article with a discussion and conclusions section.

\section{Theoretical background}

Prior research has classified IS development methods in a myriad of ways. The classification of plan-driven and the change-driven approaches [31] is based on the control concept of IS development. Pure plan- and change-driven methods are the ends of this scale. Other classifications categorize IS development methods e.g. on the basis of their heaviness [25], flexibility [32], objectives and orientation [7, 21]. We consider these classifications problematic since they overlap and are conceptually ambiguous. For example, heavyweight and change-driven methods are sometimes seen as opposites, but also heavyweight change-driven IS development projects have been conducted [20]. 
We regard the control-based classification conceptually robust and also descriptive for the practiced profession of IS development, and use it for these reasons. For our research, we selected IS projects that were close to the ends of the scale in order to describe their differences, especially as for their match to business development. The plan-driven project was executed with the waterfall stage-gate method and the change-driven project with the SCRUM method.

\subsection{Plan-driven IS development methods and assumptions about their business context}

The methods based on the plan-driven approach follow the principles of systems engineering. Royce [37] introduced the seven-step waterfall model in 1970 to manage the development of large IS. The first stage (step) is a project proposal followed by a business case and/or a feasibility study and the five stages (steps) of the actual IS development. The results of each phase (step) and often also intermediate results are evaluated to determine whether the project should be continued. In this way, the plan-driven project consists of clear phases and checkpoints, which establish stage-gates [10]. The project is executed sequentially according to a project plan. Should changes happen, the project is re-planned. Most/all current plan-driven methods are variations of the waterfall method. "Best practice" project management methods (PMBOK and PRINCE2) also follow the waterfall and stage-gate ideas. In stagegating, objectives, delivered functionalities, costs, workloads, resources and risks of the IS development and project management are specified and planned before the execution of the next phase starts [10].

The assumption regarding the business context is that objectives and deliverables of an IS development project can, and need, to be clearly defined in advance. Consequently, it is also assumed that project tasks and workloads, resources and risks are definable in advance, and that most suitable (IS) developers can be allocated to the project since needed capabilities and competences are known. Project and steering group meetings as well as checkpoints (gates) are used to ensure that the project is on the right track. Continuous risk management and mitigation activities are executed to avoid the realization of risks with high probabilities and serious adverse impacts [6].

The relation between the business context and the IS is defined during the planning phase. The current state (as-is) and the target state (to-be) of business are modelled, and actions needed to close the difference (gap) between the two states are analysed and defined. The business requirements of the IS are thus defined as a part of this analysis. Business and IS developments are then usually organized into two separate sub- projects. Business development is implemented with change management and process development methods and IS development with IS development methods.

Regarding the relation between the characteristics of the business context and the plan-driven IS methods, we tentatively conclude: plan-driven IS development methods suit to stable business contexts where both the possible business outcomes and the execution of the business (process) leading to those outcomes are known with high certainty. The characteristics of the plan-driven methods, most notably the early specification of functionalities, appear to fit well to the characteristics of these business contexts.

\subsection{Change-driven IS development methods and assumptions about their business context}

Royce warned about the limitations of his onedirectional sequential waterfall model [37]. Despite of that, change-driven IS development methods have their origin in the critique of the waterfall and other plandriven methods. Typical claims are that plan-driven methods rigidify thinking, are too mechanistic as well as create and maintain gaps between IS developers and users. IS specifications are also seen difficult to manage, change requests coming too late, and the time from specifications to an implemented IS too long. Worst of all, the environment of the organization may change during the IS development, which makes the outcome useless even if the IS implements the agreed functionalities [e.g. 19, 34].

Change-driven (agile) IS development is commonly understood to mean short development cycles resulting in a new IS release after each cycle. Although the agile IS development term was coined only some 15 years ago [3], the history of change-driven IS development methods date back to 1960 s [e.g. the Mercury project, 28]. In 1982, the idea of prototyping was launched [29] and during the $1980 \mathrm{~s}$ especially Boehm [5, 8] developed the prototyping idea further as an alternative to plan-driven (waterfall) methods. He introduced the prototyping spiral model that consists of development periods with recurring tasks during each period.

The spiral model is conceptually similar to the sprint model used e.g. in the SCRUM method [8, 17, 27, 29]. In the SCRUM method, an IS development project is executed through continuous communication between developers, users, and product owners, that is, IS project stakeholders [17]. "Rolling wave" or "phased" project planning is conducted in two phases. Some upfront planning is carried out prior the project starts and further planning is done at the beginning of each sprint. A clear vision about project objectives is the minimum planning requirement; otherwise, the IS development project has the risk of losing direction [9, 
17, 43]. Sprints could be seen as small projects. At the start of a sprint, stakeholders prioritize development needs (user stories) in a sprint-planning meeting. Selected user stories are implemented during the development period, e.g., within 2-4 weeks. At the end of the sprint, a new IS version with new/modified functionalities is released and evaluated [43]. The next sprint is then planned on the basis of the evaluative feedback and upfront planning. Even the development method is evaluated and changes are made if needed.

During a sprint, the development team members are allowed to organize their work in a way they see fit. There is no project manager nor plan-driven type project management [43]. Prior research has discovered that change-driven IS development cannot be managed with plan-driven project management methods [e.g. 42]. Similarly, there are differences between the failure reasons (risk items) of changedriven and plan-driven IS development. Project management challenges, messy software structures with maintenance difficulties and poor IS architecture compliance are some often mentioned reasons for failure [e.g. 41]. Since there are no clear plans or target descriptions, it is unclear what will be delivered at the end of a project, and what the costs, resource needs and duration of the development are. How to evaluate the quality of results and other outcomes is another unsolved issue. Customer-driven IS development projects easily lose their direction unless customers know all the time what they want. The execution of change-driven development projects rests on the availability of highly skilled individuals and their tacit knowledge since formal planning and documentation are limited. The scaling of outcome and contract negotiations have also proved challenging [e.g. 9, 31].

The stakeholders of the project discuss the relation between the IS and the business context continuously. The (business) objectives of a project are re-evaluated between each cycle and may change several times during the project. Therefore, it is possible to address uncertainties both in business execution and in business outcomes. Business related change management actions, for example, the remodelling and improvement of a business process are still left to process owners and seen as a part of the continuous dialogue between project stakeholders [3, 16, 20, 26].

Regarding the relation between the characteristics of business contexts and the change-driven IS methods, we tentatively conclude: change-driven IS development methods suit to changing and/or uncertain business contexts where both the possible business outcomes and the execution of the business (process) leading to those outcomes have high uncertainties. In such contexts, change-driven IS development methods offer means to facilitate learning, reduce uncertainties and release new IS versions rapidly and efficiently to further support learning and business development.

\subsection{Project success metrics}

In project management research, IS projects and their success are most often investigated similarly to the success of projects in general [e.g. 14, 24, 40]. We follow this tradition.

Standish Group has reported the success of IS projects annually since mid-1980s with consistent metrics. According to them, "a project is successful if it is completed on-time and on-budget, with all features and functions as initially specified" [44].These project performance metrics are called "the iron triangle" [e.g. 24], that is, IS development project performance is evaluated through cost, time and ability to deliver agreed functionalities. Project performance metrics are, however, insufficient to capture project value, such as business benefits [23, 36, 39, 48]. Prior research has reported examples of poorly performing projects that were later praised due to high business value creation.

To cover the various aspects of project success Pinto and Slevin [36] proposed a "model for project success" with six project success areas. The first three cover project performance: time, cost and the delivery of agreed outputs. The other three address project value, satisfaction and effectiveness to clients and to user organization. Similarly, Shenhar's et al [40] model divides project success into four dimensions: efficiency (time, money, delivery of agreed outputs), impact on customers, business success, and preparing for the future. The mentioned models are conceptually similar to the success measure categorizations of IT business value [e.g. 39] and IS success research [e.g. 14]. IT business value research divides IS outcome measures into performance and business value categories [39]. The six IS success measure categories of the DeLone and McLean framework [13] are system quality, information quality, use satisfaction, user satisfaction, impact on individuals and organizational impact. In summary, the abilities to adhere to the timetable and budget and to deliver agreed functionality measure project performance. Other metrics capture the present and future business value of projects to individuals and to diverse IS stakeholder groups.

\subsection{Match to organizational development}

Organizations have developed their activities by deploying technologies long before IS technologies emerged. How did organizations react to uncertainties in their capabilities to model business (processes) and the outcomes of organizational development? We 
apply Thompson's (1967) well-known twodimensional contingency model [35, 47] shown in Table 1. The vertical dimension of the model is certainty-uncertainty regarding the cause-effect relationships of organizational development, that is, whether there are uncertainties related to the capability to model current (as is) and future (to be) business execution (processes). The horizontal dimension is the certainty-uncertainty regarding outcome desirability, that is, whether there are uncertainties related to the capability to model outcomes. The model identifies four distinct strategies: 1) Computational strategy, where developed activities and outcomes are possible to "count" (=specify) in advance. 2) Judgmental strategy, where outcomes are possible to specify in advance, whereas developed activities need "judgment" between alternatives. 3) Compromise strategy, where developed activities are possible to specify in advance but outcomes need to be negotiated for a "compromise". 4) Inspirational strategy, where "inspiration" needs to be used to find a way forward [47 pp. 132-143]. In our opinion, Thompson's decision-making model for the selection of alternative organizational development strategies (Table 1) indicates how to match the characteristics of IS development methods with the characteristics of related business development contexts. Computational strategy resembles the plan-driven approach; inspirational strategy the change-driven approach; and the two others are something in between.

Table 1. Decision making strategies for organizational development [47], adapted

\begin{tabular}{|c|c|c|c|}
\hline & & \multicolumn{2}{|c|}{$\begin{array}{l}\text { Preferences regarding } \\
\text { possible outcomes (capability } \\
\text { to model outcomes) }\end{array}$} \\
\hline & & Certain & Uncertain \\
\hline \multirow{2}{*}{$\begin{array}{l}\text { Beliefs } \\
\text { about the } \\
\text { cause- } \\
\text { effect } \\
\text { relations } \\
\text { (capability } \\
\text { to model } \\
\text { business) }\end{array}$} & 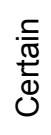 & Computational & Compromise \\
\hline & 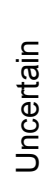 & Judgmental & Inspirational \\
\hline
\end{tabular}

\section{Research methods and IS project cases}

We examined two failed real life IS projects after their completion (ex-post). An IS development project was the unit of analysis. We deemed that two cases from the ends of the project control scale are enough to achieve limited theoretical replication [14, 49], that is, to tentatively demonstrate the usefulness of our idea to match the (certainty-uncertainty) characteristics of business development contexts and IS development methods. We selected the projects from two large organizations in different industries to minimize industry and organizational culture biases.

In the empirical research, we followed the recommendations of Eisenhardt [14] and Yin [49]. To avoid the potential risk that research questions, a-priori theoretical constructs and tentative propositions bias data analysis and limit findings [14], we sought for rival theoretical explanations (see Chapter 2). We selected the explorative case study research method for data collection and analysis reasons [49]. We used written interview and case protocols and collected data from multiple sources for triangulation [49]. In the analysis of the data, we focused on project failure reasons, on project success expectations (that were not achieved), and on the relations between the applied IS development methods and their related business development contexts. A trivial result to be expected is that the failure reasons and success expectations of the projects differ due to several anticipatable reasons [49]. An important question still is whether the collected and analysed data establish a true or even a reliable description of the investigated cases. The fact that the projects were discontinued, and because of that considered as failures, is important for the reliability and validity of the data since there were no reasons to indicate/claim anything else.

\subsection{The plan-driven IS project}

A publicly listed company with operations in over 200 locations in $70+$ countries and close to 20000 employees developed an IS to replace several legacy ISs in 2009-2010. This large project was considered business critical and received strong business executive support. The project was deemed as an IS replacement project with product data focus and no new functional requirements. The company applied waterfall and stage-gate based IS development and project management methods to execute its IS development projects and followed the IS project management guide crafted in the company for such purposes. The project team members of the case had good understanding of the methods used in the project.

Nelson [34] discovered that failures during the requirements specification phase, preceding the actual IS development, account for a large part of IS project failures in plan-driven projects. Hence, we collected significant amounts of data on how requirements and business target specifications were done with the overall objective to reveal project outcomes and their 
relation to the business context of the project. We used extensively three data collection sources of the Yin basket [49], namely documentation, archival records and interviews. A contact person from the company helped us to organize interviews and to collect documents. We defined and updated a written interview protocol to guide interviews and to select interviewees with different professional, organization hierarchy and project role backgrounds. During the recorded interviews, we observed the behaviour of the interviewees and documented observations into an interview diary. We conducted eight group-interview sessions and interviewed six persons individually after these sessions. Interviewees ranged from project to IT managers, and included the project owner and the responsible system architect. Business professionals were underrepresented. We were unable to avoid that.

We prepared semi-structured interview questions for each session/interview and continued interviewing until saturation was reached with no major new findings. During these exploratory sessions we asked interviewees to elaborate their experiences about the various methods used in the project as well as about prior IS development projects. Our contact person and an information-gathering group screened documents before they were given to us in order to prevent access to business critical product data that was irrelevant for our research. The analysed documents included project management guidelines, project reports, process models, taxonomies and planning documents.

During the data analysis, two researchers examined data independently and separately. Findings were then compared and agreed between the two researchers, discussed with a third researcher, and probed with the results of IS project failure/success research reviewed above. Finally, (in)consistencies in the alternative sources of collected data were used to triangulate the data and the findings. It is worth mentioning that a significant number of data analysis findings fall outside the scope of the present article.

\subsection{The change-driven IS project}

A university of applied sciences with over 10000 students and $30+$ educational programs, one-third international, conducted the change-driven project in 2014-2015. We collected data in 2016. The university is well known for its IS curricula, some of which have existed for decades. The university decided to develop an IS for one of its new business areas. The objective was to later roll out the new IS to the other business areas. The IS was deemed unique with no prior or comparable IS available. On the other hand, ideas were immature regarding how to execute business in the new business area and what should be the expected outcomes of the IS-enabled business development. The change-driven SCRUM method was selected to facilitate learning, continuous communication with stakeholders, and to reduce uncertainties. The existing infrastructure and other IS technologies widely used by the university were selected to limit technology risks.

Data collection differed from the company case since one of the authors had participated to the IS development project as a product owner. During the project there were, however, no plans or even hints that its outcomes would ever be investigated. Due to this, we claim that we followed the exploratory case study method also here instead of the action research method (described in e.g. in [2]). Due to this unique situation, we had access to all project documents and archival materials, such as overall project objectives, background documents, primary use cases, process models, product backlog with prioritized user stories, and test documents. The product owner / researcher's direct observation notes about participants' behaviour during face-to-face, small group and project meetings were also available to us. We still decided to use a written case protocol to guide data collection and analysis. By doing so, it became possible to establish a holistic picture of the project, and to analyse descriptions about development method selection and usage, IS and business (process) development relations and project outcomes (failure reasons and success metrics). We conducted three interviews after the analysis of documents to validate and triangulate analysis results. We also asked interviewees to confirm in writing that their interviews were documented and interpreted correctly. The presence of a researcher as a participating observer is beneficial for data collection [49]. On the other hand, such a researcher cannot act as an external observer and there is the risk to interpret the researcher's activities too positively. Data analysis and findings triangulation was otherwise done in the same way as in the plan-driven company case.

\section{Results}

\subsection{Findings: the plan-driven IS project}

The company wanted to develop and roll out a new Product Data Management (PDM) IS to all business units. Collecting requirements and IS specifications was an enormous task at the beginning of the project. Multiple teams from the diverse business units and geographical locations of the company were engaged to this task. The assumptions that legacy ISs could be replaced without functionality and business (process) enhancements were challenged almost immediately, and were among the key failure reasons of the project. 
The low quality and inconsistencies of requirements as well as communication gaps between business units and geographical locations also contributed to the failure. Complex integrations between ISs as well as educational, geographical and cultural differences were other reasons for the failure, often reported in earlier research, as well.

The insufficiency of the "golden record" approach [12] in product data harmonization was a novel failure factor with several interconnected failure reasons. From the company headquarter perspective, the business processes appeared mature and product data unified. Employees in all units had similar standing orders, manufactured similar products and offered similar customer services. Therefore, the project was deemed a legacy ISs replacement exercise that would deliver a "one company solution" by harmonizing data. Data harmonization and ISs integrations had been postponed during past mergers and acquisitions. In reality, business units and locations had dissimilar processes, which reflected the diversity of the data models in their legacy ISs. Only the physical products were commensurable. Despite of these data model challenges, the target IS was specified and IS development started. The golden record approach soon led to new problems. The "unified global master data" was a new concept to users who were familiar with their "local master data models". In local data models, the technical properties and semantic meanings of similar appearing data entities and attributes differed. These data inconsistencies created later, during the implementation phase, invincible data migration problems between the legacy ISs and the new IS. Business units and geographical locations were unwilling to use the new IS when they discovered that almost all the employees would need to change significantly their way of working. This was a surprise to IS developers, project management and executives.

In summary, we detected no major deviations from the principles of the applied methods during the project execution. Requirements for the new IS were duly collected and analysed. Target functionalities of the IS were specified. The project had clear phases and stagegates. Change management and risk mitigation were used to address the above-discussed problems. The project achieved the metrics of performance success but not business value metrics. Key project stakeholders believed both prior and during the project that the business context had no uncertainties related to business execution (processes) or business outcomes. In reality, both types of uncertainties were descriptive to the business context. Our conclusion taken from the data analysis is that the characteristics of the selected IS development methods matched poorly with the characteristics of the business development context. In other words, due to business execution and outcome uncertainties, the golden record approach induced failure reason and items intensified the impact of this mismatch between IS and business development.

\subsection{Findings: the change-driven IS project}

The change-driven project was smaller and less business critical. The initial objective of the project was to develop a minimum viable product (MVP) for thesis advisory management at the university. The purpose was to learn about this new business area and its execution, and about the deployment of relevant technologies in the new business area. Such insights could then be used to develop additional functionalities, to roll out the IS to other business areas, and to plan future development. Primary user stories were shortlisted to specify the first IS release. The technologies (platforms) deployed in the IS were widely used at the university, whereas there was less experience about the SCRUM method. The development team was therefore built so that their skills matched with the technologies and the SCRUM method, and a software contractor was recruited to develop the backend applications. Despite of all these actions, technology-related problems started almost immediately. It was impossible to fully evaluate the limits of the technologies prior the project since user needs were largely unknown. For the same reason, the IS lacked a clear software architecture. Furthermore, integrations to legacy IS were not considered. New business needs were discovered only after the project started, and the complexity of the IS solution increased rapidly. Problems became visible when the architectures of the new IS and legacy ISs clashed. Earlier studies have reported that technical risks, architecture inconsistencies, integration problems and change request management failures are typical failure reasons of change-driven IS development.

The inability of the previously widely applied technologies to cope with functionality increases was a novel failure reason with multiple failure items. Selected technologies proved unable to support new backend functionality needs in addition to architecture and integration challenges. As a consequence, the software contractor lost interest and quit. Experiments with alternative technologies led to a blind alley. These problems also contributed to the failures of mobile and desktop application development. The plan was to develop business logic and data management as serverenabled backend functionalities and to link mobile and desktop applications to them as the frontend user interfaces. The IS development started from the mobile application but ran soon into difficulties caused by the problems of the backend development. The selected 
mobile platform (windows phones) was another technology problem. University employees had windows phones as their work phones. The new IS was initially built only for this platform. New user requirements opened the IS also to other users (students), who seldom had windows phones. The costs of migrating the mobile frontend to Android and iOS were deemed too high. New functionality requirements and related increases in complexity further intensified technological problems as well as led to new skillset requirements for the project team. Changes to technologies and skillset would have required that the project had been re-started and the project team strengthened. There was no willingness to make such decisions. As the outcome of this, the project developed an unstable and non-scalable IS.

The rapid increase of business requirements was another novel failure reason that was intertwined with the technology failure reasons. The project started as a small learning-type IS development project within the new business area of the university and with limited integrations to legacy ISs. It was soon discovered that the new IS could be highly valuable to the university if it was rolled out to other business areas. (External) expectations regarding the project scope and functionalities grew continuously. New functional requirements increased both business (processes) and business outcomes related uncertainties. It would have been necessary to increase the size, the scope and the resources of the project as well as to reconsider project objectives, applied technologies, integrations to legacy ISs and influences on and from other on-going (planand change-driven) IS development projects.

In summary, we discovered that the change-driven project followed the principles of the selected SCRUM IS development method. User stories were collected and prioritised, business objectives clarified during the IS development, product backlog was updated after sprints, and the skills of the project team were matched with the technologies and the IS development method applied. The project ran into technological and project management difficulties after the expectations regarding the scope, the functionalities and other properties of the project increased fundamentally. Finally, the project drifted to a technological deadlock. Again, doing things right according the selected method was not enough; this time, the performance failed. The project achieved business value metrics (learning, growth of understanding, technology experience) but failed in performance metrics. No robust IS was delivered. Our conclusion is that the characteristics of the business context and the IS development method matched. Yet, there appears to be limits regarding the number of uncertainties that change-driven IS development methods are able to cope with. We compiled the main findings of the two cases into Table 2. The last row in Table 2 refers to the theoretical review of Chapter 2 .

Table 2. Main findings of the two cases

\begin{tabular}{|l|l|l|}
\hline Projects & Plan-driven & Change-driven \\
\hline $\begin{array}{l}\text { Characteristics } \\
\text { of the business } \\
\text { context (business } \\
\text { execution and } \\
\text { outcome } \\
\text { uncertainties) }\end{array}$ & $\begin{array}{l}\text { Unexpected } \\
\text { uncertainties related } \\
\text { to business execution } \\
\text { and outcomes were } \\
\text { discovered during the } \\
\text { project. }\end{array}$ & $\begin{array}{l}\text { Uncertainties related } \\
\text { to execution and } \\
\text { business outcomes } \\
\text { were anticipated. }\end{array}$ \\
\hline $\begin{array}{l}\text { IS project } \\
\text { execution }\end{array}$ & $\begin{array}{l}\text { No major deviations } \\
\text { from the principles of } \\
\text { selected method }\end{array}$ & $\begin{array}{l}\text { No major deviations } \\
\text { from the principles of } \\
\text { selected method }\end{array}$ \\
\hline $\begin{array}{l}\text { Performance } \\
\text { and value } \\
\text { metrics } \\
\text { outcomes of the } \\
\text { IS project }\end{array}$ & $\begin{array}{l}\text { The project achieved } \\
\text { performance success } \\
\text { metrics but not } \\
\text { business value } \\
\text { metrics. As pointed } \\
\text { out in chapter 2.3, } \\
\text { traditional project } \\
\text { success meters are } \\
\text { not enough }\end{array}$ & $\begin{array}{l}\text { The project achieved } \\
\text { some business value } \\
\text { metrics and improved } \\
\text { organizational } \\
\text { effectiveness in some } \\
\text { level (cf. [36]) but } \\
\text { failed in performance } \\
\text { metrics. }\end{array}$ \\
\hline $\begin{array}{l}\text { Match of the } \\
\text { characteristics } \\
\text { between the } \\
\text { business context } \\
\text { and the selected } \\
\text { IS development } \\
\text { method }\end{array}$ & $\begin{array}{l}\text { Selected method } \\
\text { matched poorly with } \\
\text { the characteristics of } \\
\text { the business } \\
\text { development context. } \\
\text { Based on Thompson } \\
\text { [47], an inspirational } \\
\text { approach should be } \\
\text { preferred }\end{array}$ & $\begin{array}{l}\text { Selected method was } \\
\text { correct (cf. [47]) but } \\
\text { too much } \\
\text { uncertainties increase } \\
\text { to change-driven IS } \\
\text { development method } \\
\text { to cope with (cf. } \\
\text { disorder in [41]) }\end{array}$ \\
\hline
\end{tabular}

\section{Discussion and conclusions}

We investigated one failed IS development project executed with the plan-driven approach based methods (Waterfall, stage-gate, PMBOK) and another failed IS development project executed with the change-driven approach method (SCRUM). In both cases, we discovered IS project failure reasons reported in prior studies that are typical to respective IS development methods. In addition to that, we discovered one novel failure reason for the plan-driven and two such reasons for the change-driven project.

The insufficiency of the golden record approach in product data harmonization was one of the main reasons for the failure of plan-driven PDM project. The plan-driven PDM project failed to recognize and respond to variations in the business processes and in the data models of the legacy ISs. The variations of processes and data models were strongly related to business execution and its outcomes. The changedriven project experienced difficulties with the limitations of technologies. The university had a long experience with the technologies. The project also 
experienced difficulties caused by rapidly and constantly growing scope, scale and new requirements. Also these failure reasons were tightly related to the nature of the business. This paragraph is our answer to the first research question of Chapter one.

Both projects followed the principles of the selected IS development methods without any major deviations. Doing things right according to the selected method was, however, not enough. Both projects had performance and business value success metrics although the time, money and delivery of the agreed functionalities performance metrics were truly relevant only in the plan-driven project. The plan-driven project performed as planned but failed to deliver business value to users. The change-driven project succeeded in the achievement of business value metrics but failed to perform. This paragraph is our answer to the second research question.

We suggested that there is a research gap: prior research has not considered how to match the characteristics of IS development methods and the situational development factors of business contexts where these methods are used. In the theoretical background chapter, we proposed that plan-driven methods fit well to contexts where both the business execution (processes) and the outcomes of business execution are known with high certainty. We also proposed that change-driven methods suit well to situations with high uncertainties. The findings of the two cases provide tentative and limited support to these propositions. The aim of our research was to demonstrate, with the two cases, that the proposed approach is able to offer meaningful insight and a new research venue to investigate this research gap. This paragraph is our answer to the final research question.

An obvious suggestion for future research is to probe the proposed approach with additional empirical data, for example, in addition to failure cases also in success cases. The plan-driven case showed how difficult it may be to detect whether there are uncertainties in business execution and in the outcomes of business execution. The company of the plan-driven case is highly profitable, has a strong market position, and the company is in general considered well managed. In future research, it could thus be useful to explore how to detect uncertainties in the execution of business and in the outcomes of business execution in highly successful companies. The increasing digitalization of business may also open up new ideas on how to make obscure business needs, requirements and expectations more visible and concrete.

Our study is limited to two cases. The failure reasons of the cases cannot be generalized in any way. We were not allowed to disclose the name of the global company or provide highly detailed data about the case. One of the researchers was involved in the university case. The cases were different in size, in business criticality, in global reach and both failed. These limitations may impact our findings although we did our best to validate and triangulate data and findings.

We started our article by proposing that the selection of the IS development method is returning to the agenda of strategic management. This is our invitation to both practitioners and researchers to consider and to investigate this issue. To researchers our advice is to become familiar with research done during earlier decades and to bring them to the modern digital business and open systems contexts. Our advice to practitioners is to forget the prevailing assumption that agile methods are "a silver bullet" or the only useful methods. Practitioners are advised to familiarize themselves with the limitations of methods they use.

\section{References}

[1] de Bakker, K., Boonstra, A., and Wortmann, H. Does risk management contribute to IT project success? A metaanalysis of empirical evidence. International Journal of Project Management 28, 5 (2010), 493-503.

[2] Baskerville, R.L. Investigating Information Systems with Action Research. Communications of the Association for Information Systems 2, 3 (1999), 1-32.

[3] Beck, K., Beedle, M., van Bennekum, A., et al. Manifesto for Agile Software Development. 2001.

[4] Beynon-Davies, P. Human error and information systems failure : the case of the London ambulance service computeraided despatch system project. Interacting with Computers

11, October 1992 (1999), 699-720.

[5] Boehm, B.W. Spiral Model of Software Development and Enhancement. Computer 21, 1988, 61-72.

[6] Boehm, B.W. Software Risk Management: Principles and Practices. IEEE Software 8, 1991, 32-41.

[7] Boehm, B.W. Value-based software engineering. SIGSOFT Softw. Eng. Notes 28, 2 (2003), 1-12.

[8] Boehm, B.W., Gray, T.E., and Seewaldt, T. Prototyping Vs. Specifying. IEEE Software, May (1984), 473-484.

[9] Boehm, B.W. and Turner, R. Observations on Balancing Discipline and Agility. Agile Development Conference, 2003. ADC 2003. Proceedings of the., IEEE (2003), 32-39.

[10] Cooper, R.G. Stage-Gate Systems : A New Tool for Managing New Products. Business Horizons, May-June (1990).

[11] Dahlberg, T. and Kivijarvi, H. Towards an Integrative, Multilevel Theory for Managing the Direct and Indirect Impacts of IT Project Success Factors. Proceedings of the Annual Hawaii International Conference on System Sciences, (2016), 4971-4980.

[12] Dahlberg, T., Nokkala, T., Heikkilä, J., and Heikkilä, M. Data Federation with a Governance of Data Framework Artifact as the FederationTool. Information Modelling and Knowledge Bases XXVIII 292, (2017), 31.

[13] DeLone, W.H. and McLean, E.R. Information systems 
success: The quest for the dependent variable. Information Systems Research 3, 1 (1992), 60-95.

[14] Eisenhardt, K.M. Building theories from case study research. The Academy of Management Review 14, 4 (1989), 532-550.

[15] Eveleens, J.L. and Verhoef, C. The rise and fall of the Chaos report figures. IEEE Software 27, 1 (2010), 30-36.

[16] Fernandez, D.J. and Fernandez, J.D. Agile Project Management - Agilism Versus Traditional Approaches. The Journal of Computer Information Systems 49, 2 (2008), 1017.

[17] Fitzgerald, B., Hartnett, G., and Conboy, K.

Customising agile methods to software practices at Intel Shannon. European Journal of Information Systems 15, 2 (2006), 200-213.

[18] Hansen, S. and Lyytinen, K. Challenges in contemporary requirements practice. Proceedings of the Annual Hawaii International Conference on System Sciences, (2010), 1-11.

[19] Hastie, S. and Wojewoda, S. Standish Group 2015

Chaos Report - Q\&A with Jennifer Lynch. InfoQ, blog, 2015.

https://www.infoq.com/articles/standish-chaos-2015.

[20] Henderson-Sellers, B. and Serour, M.K. Creating a Dual-Agility Method: The Value of Method Engineering. Journal of Database Management 16, 4 (2005), 1-23.

[21] Hug, C., Front, A., Rieu, D., and Henderson-Sellers, B. A method to build information systems engineering process metamodels. Journal of Systems and Software 82, 10 (2009), 1730-1742.

[22] Huisman, M. and Iivari, J. Deployment of systems development methodologies: Perceptual congruence between IS managers and systems developers. Information and Management 43, 1 (2006), 29-49.

[23] Ika, L.A. Project success as a topic in project management journals. Project Management Journal 40, 4 (2009), 6-19.

[24] Janes, A.A. and Succi, G. The dark side of agile software development. Proceedings of the ACM international symposium on New ideas, new paradigms, and reflections on programming and software - Onward! '12, ACM Press (2012), 215.

[25] Khan, M.A., Parveen, A., and Sadiq, M. A method for the selection of software development life cycle models using analytic hierarchy process. 2014 International Conference on Issues and Challenges in Intelligent Computing Techniques (ICICT), (2014), 534-540.

[26] Khan, P.M. and Beg, M.M.S. Extended Decision Support Matrix for Selection of SDLC-Models on Traditional and Agile Software Development Projects. Advanced Computing and Communication Technologies (ACCT), 2013 Third International Conference on., IEEE (2013), 8-15. [27] Larman, C. and Basili, V.R. Iterative and incremental development: A brief history. Computer 36, 6 (2003), 47-56. [28] MacManus, J. and Wood-Harper, T. Understanding the Sources of Information Systems Project Failure.

Management Services 51, 3 (2007), 38-43.

[29] McCracken, D.D. and Jackson, M.A. Life Cycle Concept Considered Harmful. SIGSOFT Softw. Eng. Notes 7 , 2 (1982), 29-32.

[30] Mitchell, S.M. and Seaman, C.B. A Comparison of
Software Cost, Duration, and Quality for Waterfall vs. Iterative and Incremental Development : A Systematic Review. Third International Symposiumm on Empirical Software Engineering and Measurement, (2009), 511-515. [31] Moe, N.B., Aurum, A., and Dybå, T. Challenges of shared decision-making: A multiple case study of agile software development. Information and Software Technology 54, 8 (2012), 853-865.

[32] Moløkken-østvold, K. and Jørgensen, M. A comparison of software project overruns-flexible versus sequential development models. IEEE Transactions on Software Engineering 31, 9 (2005), 754-767.

[33] Nandhakumar, J. and Avison, D.E. The fiction of methodological development : a field study of information systems development. Technology 12, 2 (1999), 176-191. [34] Nelson, R.R. IT project management: Infamous failure, classic mistakes, and best practices. MIS Quarterly Executive 6, 2 (2007), 67-78.

[35] Nutt, P.C. An Empirical Test of Thompson' s Model of Strategic Choice. International Journal of Business 15, 2 (2010), 159-183.

[36] Pinto, J.K. and Slevin, D.P. Project success: Definition and Measurement Techniques. Project Management Journal 19, 3 (1988), 67-73.

[37] Royce, D.W.W. Managing the Development of large Software Systems. Ieee Wescon, August (1970), 1-9. [38] Schryen, G. Revisiting IS business value research: what we already know, what we still need to know, and how we can get there. European Journal of Information Systems 22, 2 (2013), 139-169.

[39] Shenhar, A.J., Dvir, D., Levy, O., and Maltz, A.C. Project Success: A Multidimensional Strategic Concept. International Journal of Project Management 34, 6 (2001), 699-725.

[40] Shenhar, A.J., Levy, O., and Dvir, D. Mapping the dimensions of project success. Project Management Journal, 28, 2 (1997), 5-13.

[41] Snowden, D.J. and Boone, M.E. A Leader's Framework for Decision Making. Harvard Business Review 85, 11 (2007), 68-76.

[42] Sommerville, I. Software Process Models. ACM Computing Surveys 28, 1 (1996), 269-271.

[43] Sommerville, I. Software Engineering. Addison-Wesley, Boston, Massachusetts, 2011.

[44] Standish Group. The CHAOS Report. 1995.

[45] Standish Group. Chaos Manifesto: Think Big, Act Small. 2013.

[46] Theocharis, G., Kuhrmann, M., Münch, J., and Diebold, $P$. Is water-scrum-fall reality? On the use of agile and traditional development practices. International Conference on Product-Focused Software Process Improvement, Springer International Publishing (2015), 149-166. [47] Thompson, J.D. Organizations in Action: Social Science Bases of Administrative Theory. Transaction Publishers, 2003.

[48] de Wit, A. Measurement of project success. International Journal of Project Management 6, 3 (1988), 164-170.

[49] Yin, R.K. Case Study Research: Design and Methods. Sage Publications, 2009. 